East African Medical Journal Vol. 85 No. 10 October 2008

MICROBIOLOGICAL QUALITY AND SAFETY OF RASTRINEOBOLA ARGENTEA RETAILED IN KISUMU TOWN MARKETS, KENYA

A. W. Sifuna, BSc, Department of Biochemistry and Biotechnology, Kenyatta University, P.O. Box 43844, Nairobi, Kenya and Fisheries Department, P. O. Box 1084, Kisumu, Kenya, E. N. M. Njagi, PhD, Department of Biochemistry and Biotechnology, Kenyatta University, P.O. Box 43844, Nairobi, Kenya, P. Okemo, PhD, Department of Plant and Microbial Sciences, Kenyatta University, P.O. Box 43844, Nairobi, Kenya, A. Munyalo, HND, Centre for Microbiology Research, Kenya Medical Research Institute, P.O. Box 43640, Nairobi, Kenya , G. O. Orinda, PhD, Department of Biochemistry and Biotechnology, Kenyatta University, P.O. Box 43844, Nairobi, Kenya and S. Kariuki, PhD, Centre for Microbiology Research, Kenya Medical Research Institute, P.O. Box 43640, Nairobi, Kenya

Request for reprints to: Mr. A. W. Sifuna, Department of Biochemistry and Biotechnology, Kenyatta University, P.O. Box 43844, Nairobi, Kenya

\title{
MICROBIOLOGICAL QUALITY AND SAFETY OF RASTRINEOBOLA ARGENTEA RETAILED IN KISUMU TOWN MARKETS, KENYA
}

\author{
A. W. SIFUNA, E. N. M. NJAGI, P. OKEMO, A. MUNYALO, \\ G. O. ORINDA and S. KARIUKI
}

\begin{abstract}
Objective: To investigate faecal contamination and safety of Rastrineobola argentea sold in retail markets in Kisumu town.

Design: This was a repeated cross sectional study and based on random sampling. Setting: Kisumu city, targeting six markets; Oile, Jubilee, Kibuye, Kondele, Nyalenda and Manyatta.

Results: A total of 60 fish samples were analysed. All the fish were found to be contaminated with E. coli, and in addition $6.67 \%$ of the fish products tested positive for Salmonella. Shigella was absent in all samples analysed. $26.53 \%$ of $E$. coli isolates tested were resistant to two or more antimicrobial agents tested, with the highest level of resistance detected against cotrimoxazole at $38.76 \%$. The E. coli multiple antibiotic resistance (MAR) index was 0.084 indicating that the contamination was not originating from a high - risk source. A plasmid of approximately $5.6 \mathrm{~kb}$ was commonly isolated from $E$. coli isolates that showed resistance to ampicillin. Plasmids isolated were not transferable by conjugation.

Conclusion: The presence of Salmonella spp and occurrence of MDR E. coli were identified as some of the possible health risks that may be associated with $R$. argentea displayed for sale in Kisumu city markets. This possess a real health risk through consumption or directly through contact with the fish products.
\end{abstract}

\section{INTRODUCTION}

Rastrineobola argentea (omena or dagaa) is among the most important commercial fish species of Lake Victoria, it is a relatively cheap source of animal protein for man and livestock and its demand is substantially increasing, as other protein sources such as beef and poultry get expensive (1). The product is marketed at retail markets as whole sun dried fish. Although $R$. argentea plays an important role in the socio-economic development of rural areas and is of critical importance in meeting the food security and nutritional requirements of riparian communities, data on health risks associated with consumption of fish and fish products particularly $R$. argentea is lacking. Several studies have reported on incidences of pathogenic bacteria such as Staphylococcus spp, Shigella spp, Salmonella spp and Vibrio spp in fish and fishery products and these could pose major health risks to consumers $(2,3)$. Rastrineobola argentea fishing takes place at night using canoes that do not have any form of cold storage for the catch. For preservation drying is usually done on the ground at the landing beaches leading to contamination with sand, flies and possibly 
microorganisms. The dried products are similarly exposed to further contamination during storage, transportation and sale at open-air markets (4).

Food products that show evidence of faecal contamination are generally regarded as a greater risk to human health, as they are more likely to contain human-specific enteric pathogens. Indicator microorganisms in food microbiology have been used to predict the presence of potential risks associated with pathogenic microbes. Among the enteric bacteria, Escherichia coli is always considered to be of faecal origin, and exists only transiently in other environments (5). E. coli is also found in abundance in almost any moist environment, notably soil, water and the domestic environment (6).

Ahigh prevalence of antibiotic resistance is often encountered in Enterobacteriaceae of human origin $(7,8)$.Irrational usage of antibiotics has beenidentified as an important factor that promotes the emergence, selection and dissemination of antibiotic - resistant microorganisms in both veterinary and human medicine $(9,10)$. Locally, few resistance data exist for populations outside of the clinical environment, though this is vitally important for understanding the dynamics of the spread of antimicrobial resistance. The aim of the present study was to document the level of faecal contamination of sundried $R$. argentea based on faecal coliform counts, and presence of enteric pathogens including E. coli, Salmonella and Shigella spp. The study also investigated presence of plasmids as mediators of resistance to antimicrobials among bacterial isolates.

\section{MATERIALS AND METHODS}

Collection of fish samples: Samples of $R$. argentea were collected from six fish markets in Kisumu town. A total of 60 fish samples were purchased in regular consumer packages (500g tins - approximately $100-150 \mathrm{~g}$ of $R$. argentea). The samples were immediately transported aseptically to the Fish Quality Laboratory in Kisumu for analysis. The sample design was a repeated cross sectional study based on random sampling.

Bacteriological analysis: The analysis of omena products for faecal coliforms (FC) and E. coli were performed according to FDA bacteriological analytical manual (11) using violet red bile agar (VRBA) (Oxoid, Basingstoke, UK) and incubated at $44.5^{\circ} \mathrm{C}$ for 48 hours. Characteristic E. coli colonies were selected for further identification and confirmation by morphological and biochemical tests (12). Presence of Salmonella and Shigella was detected using the FAO food and nutrition paper 14 / 4 rev.1 (13). Briefly, selenite cystine broth (Oxoid) and tetrathionate broth (Oxoid) were used for enrichment of fish samples. Xylose Lysine Desoxycholate (XLD) agar (Oxoid,) Mac Conkey (Oxoid) and Bismuth sulfite (BS) agar (Oxoid) were used for selection of all presumptive positives cultures and colonies were then identified by biochemical and serological tests (12).

Antibiotic susceptibility testing: One E. coli colony was chosen randomly from each sample. The standard Kirby-Bauer disk diffusion method was used to determine the susceptibility to ten antimicrobial agents (ampicillin $10 \mu \mathrm{g}$, tetracycline $30 \mu \mathrm{g}$, cotrimoxazole $25 \mu \mathrm{g}$, augmentin $30 \mu \mathrm{g}$, gentamicin $10 \mu \mathrm{g}$, kanamycin $30 \mu \mathrm{g}$, cefuroxime $30 \mu \mathrm{g}$, chloramphenicol $30 \mu \mathrm{g}$, nalidixic acid $30 \mu \mathrm{g}$ and norfloxacin $10 \mu \mathrm{g}$ ) using the protocol in the NCCLS manual (14). The plates were incubated at $37^{\circ} \mathrm{C}$ for 18 hours. A standard reference strain of $E$. coli (ATCC 25922) was used as control for growth of bacteria and potency of antibiotic disks.

Plasmid analysis: Plasmids were isolated using the method of Kado and Liu (15). Samples were analysed by electrophoresis on horizontal $1 \%$ agarose gel in $0.5 \mathrm{X}$ TBE buffer at $125 \mathrm{~V}$ for 2 hours. Plasmid sizes were determined by co-electrophoresis with plasmids of known sizes for E. coli strains V517 (53.7, 7.2, 5.6, 3.9, 3.0, 2.7, $2.1 \mathrm{~kb})$ and 39R861 $(147,63,43.5,6.9$ $\mathrm{kb})$. DNA bands were visualised with an ultraviolet transilluminator (UVP inc.) after staining with $0.05 \%$ ethidium bromide.

In-vitro conjugativeexperiments: To determine mobility of antibiotic-resistance genes, in-vitro conjugation was carried out as described previously by Yamamoto and Yokota (16) using E. coli K-12 (nalidixic acid resistant) as recipient. Transconjugants were then selected on MacConkey agar supplemented with nalidixic acid $(30 \mu \mathrm{g} / \mathrm{ml})$ and ampicillin $(30 \mu \mathrm{g} / \mathrm{ml})$. To determine the transferable antibiotic resistance, transconjugants were tested for susceptibility to the battery of antibiotics previously used for isolates.

Statistical analysis: The data collected was entered in Microsoft Excel (windows XP Professional) spreadsheet and analysed and confidence levels of 95\% were considered significant. The means ( $\mu$ ) FC and antimicrobial agents for the $R$. argentea were estimated for each market. Analysis of variance was used to determine differences between and within markets and antimicrobial agents tested respectively. The MAR index was calculated based on the formula described by Krumperman (17); a / (b xc), where a; is the aggregate antibiotic resistance score of all isolates from the sample, $b$; is the number of antibiotics, and $\mathrm{c}$ is the number of isolates.

\section{RESULTS}

All the markets surveyed showed FC means above those recommended by theKenyaBureau of Standards zero (0) faecal coliforms (Table 1). Oile market 
demonstrated the highest levels of contamination $\left(\log _{10} 4.33 \mathrm{cfu} / \mathrm{g}\right)$ whereas Kibuye market registered the lowest level at $\log _{10} 3.62 \mathrm{cfu} / \mathrm{g}$. The study did not find any significant difference among the sampled markets relating to the faecal coliform load (FC) $[\mathrm{P}>0.05]$. E. coli were isolated from all the 60 fish products examined, while Salmonella was present in four samples $(6.67 \%)$. Two isolates were identified as serovar enteritidis; one each as serovar typhimurium and serovar paratyphi B. No Shigella spp was isolated from the samples.

All E. coli isolates were fully susceptible to chloromphenicol, nalidixic acid and norfloxacin (Table 2). A total of 12 distinct antibiogram patterns were observed (Table 3). Fourty seven percent isolates showed resistance to at least one or more antimicrobial agent tested. Isolates were most frequently resistant to cotrimoxazole $(38.8 \%)$, tetracycline $(20.4 \%)$ and ampicillin (12.2\%). $26.5 \%$ of the isolates tested showed resistance to two or more antimicrobial agents. Multiple antibiotic resistance (MAR) index of 0.084 was obtained for the E. coli contamination.

No plasmid was transferable by conjugation. A total of six different plasmid profiles were seen among the E. coli isolates. All the isolates that showed resistance to ampicillin had a common plasmid of approximately $5.6 \mathrm{~kb}$. The most frequent plasmids observed among the isolates were those of approximately $5.6 \mathrm{~kb}$ or less; plasmids of molecular weights greater than $5.6 \mathrm{~kb}$ were observed in only two isolates.

Table 1

Levels of faecal contamination of $R$. argentea by various markets sampled in Kisumu city ( $n=10$ for each market)

\begin{tabular}{lccc}
\hline Markets & \multicolumn{1}{c}{ Range } & Mean & Mean $\log _{10} \mathrm{cfu} / \mathrm{g}$ \\
\hline Oile & $2.5 \times 10^{2}-6.4 \times 10^{5}$ & $1.34 \times 10^{5}$ & $4.33 \pm 1.07$ \\
Jubilee & $1.0 \times 10^{1}-5.0 \times 10^{5}$ & $1.87 \times 10^{5}$ & $4.27 \pm 1.54$ \\
Kibuye & $2.3 \times 10^{2}-8.8 \times 10^{5}$ & $1.03 \times 10^{5}$ & $3.62 \pm 1.23$ \\
Kondele & $2.0 \times 10^{1}-7.2 \times 10^{5}$ & $1.80 \times 10^{5}$ & $4.33 \pm 1.48$ \\
Nyalenda & $2.8 \times 10^{2}-8.4 \times 10^{5}$ & $1.60 \times 10^{5}$ & $4.32 \pm 1.13$ \\
Manyatta & $1.8 \times 10^{2}-4.0 \times 10^{5}$ & $7.92 \times 10^{4}$ & $3.91 \pm 1.08$ \\
\hline
\end{tabular}

Table 2

Antimicrobial susceptibility of E. coli isolates by antimicrobial agent

\begin{tabular}{lcccccc}
\hline \multirow{2}{*}{ Antimicrobial agent } & \multicolumn{2}{c}{ Resistant } & \multicolumn{3}{c}{ Intermediate } & \multicolumn{2}{c}{ Susceptible } \\
& No. & $(\%)$ & No. & $(\%)$ & No. & $(\%)$ \\
\hline Ampicillin & 6 & 12.24 & 0 & 0 & 43 & 87.76 \\
Tetracycline & 10 & 20.41 & 11 & 22.45 & 28 & 57.14 \\
Cotrimoxazole & 19 & 38.76 & 2 & 4.08 & 28 & 57.14 \\
Augmentin & 2 & 4.08 & 5 & 10.2 & 42 & 85.71 \\
Kanamycin & 2 & 4.08 & 25 & 51.02 & 22 & 44.90 \\
Gentamicin & 1 & 2.04 & 3 & 6.12 & 45 & 91.84 \\
Cefuroxime & 3 & 6.12 & 43 & 87.76 & 3 & 6.12 \\
Chloromphenicol & 0 & 0 & 0 & 0 & 49 & 100 \\
Nalidixic acid & 0 & 0 & 0 & 0 & 49 & 100 \\
Norfloxacin & 0 & 0 & 0 & 0 & 49 & 100 \\
\hline
\end{tabular}

Table 3

Antibiogram patterns of E. coli isolates from R. argentea

\begin{tabular}{lccc}
\hline Resistance pattern & No. of strains & Resistance pattern & No. of strains \\
\hline Cot & 9 & Amp + Cot & 2 \\
Crx & 1 & Tet + Cot & 3 \\
Tet & 1 & Amp + Tet + Cot & 2 \\
Cot+Kan & 1 & Amp + Tet + Aug & 1 \\
Tet+Aug & 1 & Tet + Crx & 1 \\
Amp+Tet+Cot+Gen & 1 & Cot +Kan + Crx & 1 \\
\hline
\end{tabular}

Cot = Cotrimoxazole, Crx = Cefuroxime, Tet = Tetracycline, Kan = Kanamycin, Aug = Augmentin,

Gen $=$ Gentamicin, Amp $=$ Ampicillin 


\section{DISCUSSION}

Faecal coliform contamination were observed in all the $60 \mathrm{R}$. argentea samples tested. This would imply that the fish being sold in Kisumu city markets is of low microbial quality and does not comply with the locally laid down standards for sundried $R$. argentea (18). The source of contamination of the fish products was common among the markets. This could be attributed to the operations through which the fish undergoes during harvesting, processing and handling $(19,20)$. Good hygiene practices (GHP) and hazard analysis critical control point (HACCP) are not operational along the production, processing and distribution line and these may explain such findings. GHP and HACCP are important tools for managing and ensuring that food products are produced under hygienic conditions and that food safety measures are in place to address all possible risks that may be associated with the food product.

The study however observed that the contamination based on the MAR indexing of E. coli was lower than 0.200 , suggesting that the contamination may have arisen from a low risk source (17). The occurrence of Salmonella spp in some samples collected from the market and absence of Shigella spp strongly supports the existence of other high-risk sources within the geographical limits of the study that are not exposed directly to antimicrobials. Salmonella have a wide range of warm-blooded animals, including human beings as hosts whereas Shigella spp are restricted tohigher primates, including humans and usually spread among humans by food handlers with poor personal hygiene (11). Based on our findings we would like to suggest that MAR indexing of E. coli alone may not be a good indicator of risk assessment of food products and especially those sourced from the wild, as there are other risk sources that MAR indexing of E. coli may not be able to detect since the intensive rearing of livestock is least practiced in the region.

In this study E. coli isolates showed relatively low level of resistance to antimicrobial agents tested compared to clinical isolates in other studies conducted locally (21). Our study agrees with Österblad et al., (22) who found a very low frequency of antimicrobial resistance in Enterobacteriaceae isolated from vegetables although very few E. coli were isolated suggesting that faecal contamination was rare. The prominence of co-trimoxazole, tetracycline and ampicillin resistance among $E$. coli isolates in our study demonstrates the similarities in the development of resistance among the isolates and the E. coli of clinical importance. We therefore postulate that this exposure to antibiotics might be of a human origin. This is further supported by the presence of resistance to co-trimoxazole, a synthetic antibiotic generally used in humans only. The differences in levels of resistance and resistance patterns could be due to levels of exposure to the agents or other factors that may have increased or decreased the likelihood of the development and conservation of resistant bacteria. $R$. argentea is not exposed directly to antibiotics but may be contaminated with antibiotic resistant bacteria through personnel, polluted fishing grounds or animal droppings.

The study also found that isolates recovered from Kondele market showed the smallest mean diffusion zones for all the antimicrobial agents except for cefuroxime. This may indicate that there were other sources or practices that may have contributed to contamination of products or exposure to resistant bacteria within this market, which were not sampled in this study. Rysz and Alvarez, (23) demonstrated that bacteria in the soil can acquire resistance to tetracycline from environmental exposure, possibly creating a reservoir of resistance factors generated outside host animals. General observations indicated that the market is not designated and is situated on a road reserve; no sanitary facilities and solid waste management measures were available. The study also found significant differences in rates of E. coli resistance to tetracycline within the markets $(\mathrm{P}<$ 0.05). Tetracycline has for along time been used as a first-line antibiotic for many different species of domestic animals. Resistance to tetracycline is plasmid mediated, with a wide variety of genetic determinants, making it more prone for susceptible bacteria to acquire these resistance factors (24).

A plasmid of approximately $5.6 \mathrm{~kb}$ was more frequent among the isolates. Sherley et al., (25) observed that the majority of E. coli strains wildtype carried one or more plasmids, which varied in size, but $45 \%$ of the isolates from the plasmid bearing strains had plasmids smaller than $16 \mathrm{~kb}$ in size. In contrast, similar studies on clinical isolates involving the Enterobacteriaceae family have found plasmids of $100 \mathrm{~kb}-110 \mathrm{~kb}$ responsible for conjugative transfer of ampicillin, tetracycline, cotrimoxazole, and chloromphenicol resistance $(21,26,27)$. Since the isolates were obtained from $R$. argentea sourced from markets, and based on the fact that the bacterial contamination may be from rural sources (based on MAR index of E. coli) such as the villages along the lake shores where the fish was processed, it is possible that the bacterial isolates may not favourably maintain large conjugative plasmids encoding for resistance to antimicrobial agents. However, in other studies small plasmids of $<10 \mathrm{kbp}$ have been reported to mediate single cross-resistance to ampicillin, tetracycline, sulfonamide and streptomycin (28).

In conclusion, our data provides evidence for significant faecal contamination and the presence of Salmonella, and antimicrobial resistant E. coli in $R$. argentea sold on markets in Kisumu, posses a real health risk through consumption or directly through contact with the fish products including livestock that may feed on contaminated animal feeds produced from $R$. argentea. It will be important for public health workers to create awareness for the need to institute GHP and HACCP as tools for ensuring that fish 
products are produced under hygienic conditions and that food safety measures are in place. Long term prospective studies to examine isolates from $R$. argentea, including microbial source tracking, are required to give more accurate, temporal and spatial information on the levels and characteristics of faecal contamination.

\section{ACKNOWLEDGEMENTS}

To the Ministry of Livestock and Fisheries Development for providing financial support and to Mr. Boniface Achuma of Government Chemist Laboratories Kisumu, for his diligent support during sampling and sample processing.

\section{REFERENCES}

1. G.O.K. Fisheries Department Annual Report 2002.

2. Bryan, F.L. Epidemiology of foodborne diseases transmitted by fish, shellfish and marine crustaceans in the United States, 1970 - 1978. J. Food Prot. 1980; 43: 859 - 876 .

3. Bryan, F. L. Seafood - transmitted infections and intoxications in recent years. In: Seafood Quality Determination. Eds:D.E. Kramer and J. Liston. Elsevier Science Publishers. 1987; 319 - 337.

4. Abila, R.O., and Jansen, G.K. From local to global markets: The fish export and fish meal industries of Lake Victoria - structure, strategies and socioeconomic impacts in Kenya. IUCN Eastern Africa Programme-Socio-economics of the Lake Victoria Fisheries. 1997. Report No.2, $20-25$.

5. Markie, R. I., White, B. A and Isaacson, R. E. Gastrointestinal microbiology: Gastrointestinal Microbes and Host Interactions, Vol. 2. Chapman and Hall, NewYork. 1997.

6. Scott, E., Bloomfiel, S. F. and Barlow, C.G. An investigation of microbial contamination in the home. J. Hyg. 1982: 89: 279 - 293.

7. McGowan, J. E., Hall, E.C. and Parrott, P.L. Antimicrobial susceptibility in gram - negative bacteremia: are nosocomial isolates really more resistant? Antimicrob. Agents Chemother. 1989;33:1855 $-1859$.

8. White, A. C., Atmar, R. L., Wilson, J., et al. Effects of requiring prior authorization for selected antimicrobials: expenditures, susceptibilities and clinical outcomes. Clin. Infect. Dis. 1997; 25: 230 $-239$.

9. Neu, H. C. The crisis in antibiotic resistance. Science. 1992; 257: 1064-1073.

10. Witte, W. Medical consequences of antibiotic use in agriculture. Science. 1998; 279: 996-997.

11. FDA. Bacteriological Analytical Manual (Online) Enumeration of Escherichia coli and the Coliform Bacteria http://www.cfsan.fda.gov/ ebam/bam-4.html 10/04/2005. 2003.

12. Cheesbrough, M. Medical Laboratory Manual for Tropical Countries. Vol. II: Microbiology. ButterworthHeinemann Ltd. England. 1984.
13. FAO Food and Nutrition Paper 14/4 Rev. 1: manual of food quality control 4. Revision.I. Microbiological analysis, 9 - 26. 1992.

14. NCCLS. NCCLS document M 100-S9. Performance standards for antimicrobial susceptibility testing, $9^{\text {th }}$ edition. Information supplement. National Committee for Clinical Laboratory Standards, Wayne, Pa. 1999

15. Kado, C.I. and Liu.S. T. Rapid procedure for detection and isolation of large and small plasmids. J. Bacteriol. 1981; 145: 1365 - 1373

16. Yamamoto, T. and Yokota, T. Plasmids of enterotoxigenic Escherichia coli H104O7: evidence for two heat-stable enterotoxin genes and a conjugal transfer system. J. Bacteriol. 1983; 153: 1352 - 1360.

17. Krumperman, P.H. Multiple antibiotic resistance indexing of Escherichia coli to identify high - risk sources of fecal contamination of foods. Appl. Environ. Microbiol. 1983; 46: 165 - 170.

18. Kenya Bureau of Standards. Specification for dried Rastrineobola argentea (omena dagaa): KS 051470:1998

19. Huss, H. H. Assurance of seafood quality. FAO Fisheries Technical Paper: 334; Food and Agriculture Organisation, Rome, Italy. 1994.

20. Ogwan'g, V. O., Muchiri, M., and Thakor, P. Investigation of bacteriological quality of smoked fish. In: Knowledge and experiences gained from managing The Lake Victoria Ecosystem, a publication of the Lake Victoria Environmental Management Project (LVEMP) 2005. pp. $552-569$

21. Kariuki, S., Gilks, C., Kimari, J., et al. Genotype analysis of $E$ coli strains isolated from children and chicken living in close contact. Appl. Environ. Microbiol. 1999; 65: 472- 476 .

22. Osterblad, M., Pensala, O., Peterzens, M., et al. Antimicrobial susceptibility of Enterobacteriaceae isolated from vegetables. I. Antimicrob. Chemother. 1999; 43: 503-509.

23. Rysz, M., and Alvarez, P. J. J. Amplification and attenuation of tetracycline resistance in soil bacteria: aquifer column experiments. Water Res. 2004;38:3705 $-3712$.

24. Prescott, J.F., Baggot, J. D and Walker, R. D (ed). Antimicrobial therapy in veterinary epidemiology, $3^{\text {rd }}$ edition. Iowa State University Press, Ames. 2000

25. Sherley, M., Gordorn, D. M and Collignon, P.J. Species differences in plasmid carriage in the Enterobacteriaceae. Plasmid. 2003; 49: 79 - 85.

26. Karuki, S., Ravathi., G., Gakuya, F., et al. Lack of clonal relationship between non-typhi Salmonella strain types from humans and those isolated from animals living in close contact. FEMS Immunol. Med. Microbiol. 2002; 33: 165 - 171.

27. Kariuki S., Revathi., G., Kariuki, N., et al. Increasing prevalence of multidrug - resistant non-typhoidal salmonellae, Kenya, 1994 - 2003. Int. J. Antimicrob. Agents. 2005; 25: 38 - 43 .

28. Vorland, L. H., Carlson. K and Aalen, O. Antibiotic resistance and small $\mathrm{R}$ plasmids among Escherichia coli isolates from outpatient urinary tract infections in Northern Norway. Antimicrob. Agents Chemother. 1985; 27: $107-113$. 